\title{
Simulation Study on Series Capacitor Compensation to Improve the Voltage Quality of Rural Power Distribution Network
}

\author{
Hongqiang Li, Feng Gao, Xutao Li, Shaogui Ai, Shuang Zhang, Bei Tian \\ State Grid Ningxia Electric Power Research Institute, Yinchuan, China \\ Email: lhq1652@126.com
}

Received 7 September 2015; accepted 16 October 2015; published 23 October 2015

\begin{abstract}
In order to improve the voltage quality of rural power distribution network, the series capacitor in distribution lines is proposed. The principle of series capacitor compensation technology to improve the quality of rural power distribution lines voltage is analyzed. The real rural power distribution network simulation model is established by Power System Power System Analysis Software Package (PSASP). Simulation analysis the effect of series capacitor compensation technology to improve the voltage quality of rural power distribution network, The simulation results show that the series capacitor compensation can effectively improve the voltage quality and reduce network losses and improve the transmission capacity of rural power distribution network.
\end{abstract}

\section{Keywords}

Series Capacitor Compensation, Rural Power Distribution Network, The Quality of Voltage, PSASP, Simulation

\section{Introduction}

For a long time, the rural power grids were not enough attention because of systematic causes, investment and rural power grid at the end of grid and other reasons, so its construction and development is seriously lagging behind with respect to the transmission grid, urban distribution network. The structure of rural power distribution network is relatively weak, irrational distribution, equipment aging and power supply radius is longer, the peak-valley of rural load is large, the seasonal of rural load is strong, the power line are dispersed, the more distribution transformers, the natural power factor is low, these factors lead to the rural power transmission loss larger, low efficiency and the lower voltage at the end of the line, voltage drop seriously, seriously affect the normal use of electrical equipment users.

The main measures to solve the problem of lower voltage at the end of the rural power lines have changing the transformer tap position, replacing larger diameter wire and increasing the power point and using the distributed shunt reactive compensation devices [1]. The first method is the easiest to implement, but its regulation range is limited; the second method has high investment costs; the third method is currently most used for im- 
proving the power factor and reducing power lines loss which has played a significant effect. But ordinary switching shunt capacitor compensation devices have frequent switching operation, lower response, great maintenance work and poor compensation accuracy, when the line is overloading, reactive power compensation is lower, the voltage boosting effect is not obvious; when the load of the line is light, the line voltage will increase. In recent years, although SVC, STATCOM and other reactive compensation equipment based power electronics technology developed rapidly, it’s failed to large-scale applications in rural power distribution network because of its high costs, high maintenance [2].

In addition to the above three measures, there is measure that series capacitors in the circuit, it has a significant effect for improving voltage profile along the radial distribution lines, reducing the voltage drop and increasing transmission line capacity. Currently the technology of series capacitor has been widely used in the high voltage transmission line at home and abroad [3] [4], it also has a certain application in the low voltage distribution network in the United States and Europe [5], but little applications in the domestic rural power distribution network.

This paper analyzes the basic principle of series compensation technology to improve the quality of rural power distribution network. Then the effect of series capacitors compensation technology improving rural power distribution network voltage quality and transmission line capacity is simulation analyzed by Power System Power System Analysis Software Package (PSASP) based a real Ningxia rural power distribution lines. Finally, a number of issues should be payed attention in the series capacitors compensation practical application is introduced.

\section{Basic Theory}

\section{A. Characteristics of series capacitor on transmisson capacity}

Series capacitors compensation was first applied in the field of high voltage transmission technology, its technology development is more mature. The impact of series capacitor compensation on transmission line capacity is analyzed by a simple double-machine system. The analyzed system is shown in Figure 1.

The active power of the system without series capacitor can be written as:

$$
P=\frac{U_{1} U_{2}}{X_{L}} \sin \delta
$$

The active power of the system with series capacitor can be written as:

$$
P=\frac{U_{1} U_{2}}{X_{L}-X_{C}} \sin \delta
$$

So adding a series capacitor to a power transmission lines equivalent to reducing the electrical distance between two systems, the transmission capacity of the power lines is improved.

\section{B. Characteristics of series capacitor on line voltage}

The voltage performance of the lines without series capacitors can be illustrated series circuit shown in Figure 2, which represents a typical rural power distribution network consisting of a series resistance $R_{L}$ and a series inductive reactance $X_{L}$.

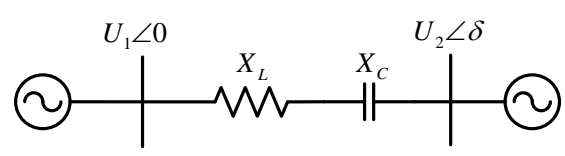

Figure 1. Double machine system with series capacitor.

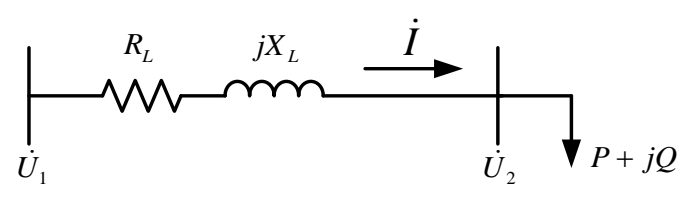

Figure 2. A type rural power distribution network without series capacitor. 
where

$U_{1}=$ the voltage of first end of the line.

$U_{2}=$ the voltage of tail end of the line.

$I=$ the current of line.

$P+j Q=$ the apparent power of load.

The phasor diagram for inductive load of the circuit is shown in Figure 3: where

$\varphi=$ power factor angle of the load.

$\theta=$ power factor angle of first terminal of the line.

The voltage drop per phase from source to load is obtained from the phasor diagram in Figure 3:

$$
\begin{aligned}
\Delta U & =\sqrt{3}\left(U_{R} \cos \varphi+U_{L} \sin \varphi\right) \\
& =\sqrt{3}\left(I R_{L} \cos \varphi+I X_{L} \sin \varphi\right) \\
& =\frac{P R_{L}+Q X_{L}}{U_{1}}
\end{aligned}
$$

From the (3), if the load is inductive, the voltage at the end of the line is lower than the voltage at the head of the line. An inductive load causes a voltage reduction at the load.

Consider the circuit in Figure 4, which added a series capacitor, its capacitive reactance term is $X_{C}$. The phasor diagram for inductive load of the circuit is shown in Figure 5.

From the Figure 5, the voltage drop per phase from source to load can be written as:

$$
\begin{aligned}
\Delta U & =\sqrt{3}\left(U_{R} \cos \varphi-\left(U_{C}-U_{L}\right) \sin \varphi\right)=\sqrt{3}\left(I R_{L} \cos \varphi+I\left(X_{L}-X_{C}\right) \sin \varphi\right) \\
& =\frac{P R_{L}+Q\left(X_{L}-X_{C}\right)}{U_{1}}
\end{aligned}
$$

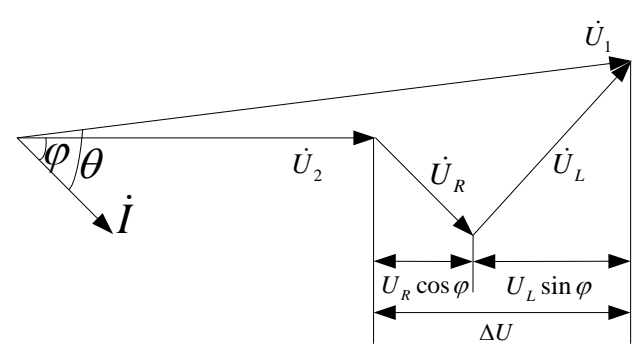

Figure 3. Phasor diagram for inductive load of the circuit without series capacitor.

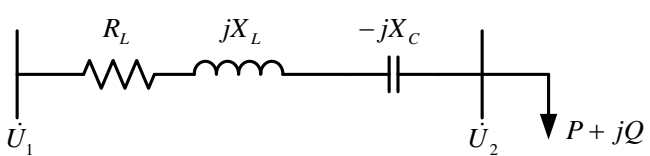

Figure 4. A type rural power distribution network with series capacitor.

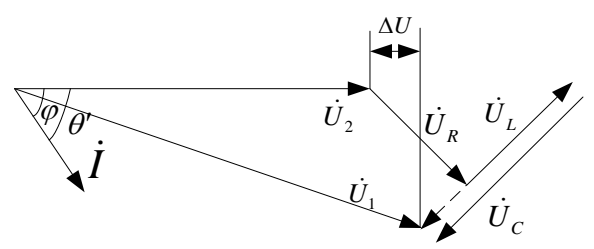

Figure 5. Phasor diagram for inductive load of the circuit with series capacitor. 
From the (4), the series capacitor reduced the voltage drop of the lines, it provide a voltage $U_{C}$ which is opposite of the reactance voltage, where $U_{C}=\sqrt{3} I X_{C} \sin \varphi$, it is proportional to the line current, and is inversely proportional to the power factor of the line; it also is automatically changing rapidly and continuously with the changing load, the heavier the load, the larger the current, the larger the $U_{C}$, the voltage drop will be smaller, the voltage boost effect is more obvious. On the other hand, the lighter the line load, the smaller the $U_{C}$, the voltage boost effect is not obvious. At the same time, if the suitable capacitor is selected, the series capacitor can effectively reduce the voltage fluctuations caused by the load fluctuations.

The power loss of the line can be written as:

$$
P_{\text {loss }}=I^{2} R_{L}
$$

Under certain active power of line circumstances, after adding a series capacitor, the line voltage will increase, the line current will reduce, thus the line power loss will reduced.

From the Figure 3 and Figure 5, we can also obtain that the power factor at the sending end of lines will increase if a series capacitor is added in the line.

\section{Simulation Analysis}

In the paper, a real rural power distribution network lines in Ningxia is taken for example, its simulation model was established by the Power System Analysis Software Package (PSASP), Simulation analysis the effect of series compensation capacitor to the voltage. Quality of the lines.

\section{A. The established simulation model}

We usually can obtain the length of total lines, the type of the main line and branch line, the number, location and its characteristic of the load and the capacity of the distribution transformers from the power supply company.

In general, the trunk lines of distribution lines are longer, the brunch lines are more, load type is also different. So if the all the lines and load are detailed modeling will undoubtedly increase the workload. Moreover the main propose of this paper is to assess the line voltage; there is no need to model all the elements. Therefore it is necessary to simplify the model appropriately. Ensuring the total length of trunk lines unchanged, reducing the number of load nodes on trunk lines, short distance between adjacent load nodes may be combined into one load point, its size is the sum of both, and its location is farthest location from the power source, All the load of the short brunch lines can be moved to the trunk line. The impedance of brunch and all the transformers are ignored.

The load power, current and its power factor of brunch lines are difficult to collect. So the size of each load can be estimated on basis the load rate of the distribution transformer capacity.

The total capacity of the selected line transformer is $13,875 \mathrm{kVA}$ in this paper, the distance between two adjacent towers is averagely $81 \mathrm{~m}$, the distance between the first and the tail end of the line is approximately 21 km. Its simplified simulation model is shown in Figure 6.

\section{B. The simulation results without series capacitor}

According to the established model, the voltage profile is simulated and analyzed under three different power factor and load rate. Simulation results are shown in Figure 7.

According to the simulation results, when the load average power factor is 0.85 , the load rate is higher than $69 \%$, the power flow will not converge. When the load rate is $69 \%$, the voltage at the end of line drops to 4.65 $\mathrm{kV}$; when the load rate is less than $25 \%$, the voltage at the end of line will higher than $9.3 \mathrm{kV}$ which is in line with the distribution network voltage quality requirements. Therefore the transmission capacity of this line is quite smaller. We also can be seen from the Figure 7, when the load rate is $69 \%$, the power factor is $0.95,0.9$, 0.85, the voltage at the end of line drops to $6.09 \mathrm{kV}, 5.45 \mathrm{kV}, 4.65 \mathrm{kV}$. Therefore, under the same load rate, the lower the power factor of the line, the lower the voltage at the end of line, the greater the voltage drops.

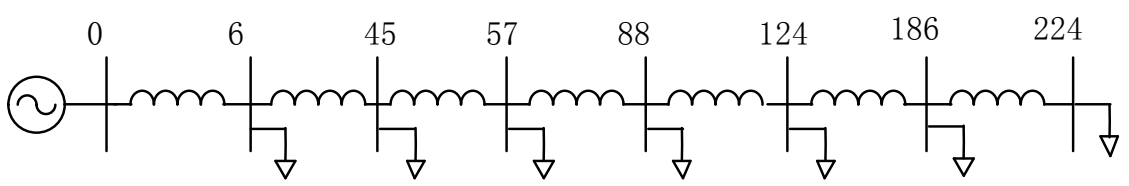

Figure 6. The simplified simulation model without series capacitor. 


\section{The simulation results with series capacitor}

Rural power distribution lines is longer, the series compensation capacitor mounting position not only has greater effect on the compensation effect, but also affect the choice of the its capacity, so the series compensation capacitor installation location should solve the voltage quality of the lines, at the same time, the number of the capacitor installation and its capacity should reach the minimum as much as possible.

In order to improve the voltage profile along the line, the series capacitors installation location can be closer to the power point and the location of the largest voltage drop. It can be contained from the Figure 7, the voltage drop is largest at the 57 Tower, its voltage has dropped to $8.12 \mathrm{Kv}$, so the series capacitor can be installed after the Tower 57.

The value of series capacitor can be obtained from the $\mathrm{k}$ called degree of compensation, with reference to Figure 8.

We can write the degree of compensation as follows:

$$
k \%=\frac{X_{C}}{X_{E}} \times 100 \%
$$

where:

$X_{c}=$ capacitive reactance of the series capacitor $(\Omega)$

$X_{E}=X_{1}+X_{2}+X_{3}+X_{4}(\Omega)$

$X_{E}$ is defined to include the total inductive reactance from source to the location of the series capacitor.

A value of $\mathrm{k}$ greater than $100 \%$ is called overcompensation; the overcompensation will increase the risk of the ferroresonance, but in order to achieve the best voltage profile along the circuit. The value of $k$ is selected to be greater than the $100 \%$. Therefore if overcompensation is considered, the problems that might occur are recommended.

Based on the above analysis, the capacitance of the series capacitor located behind 57 Tower is $6 \Omega$, the simulation equivalent single-line diagram is shown in Figure 9.

The power factor of the line is 0.9 , the load rate is $69 \%$, and the voltage profile along the line is shown in the

\section{Figure 10.}

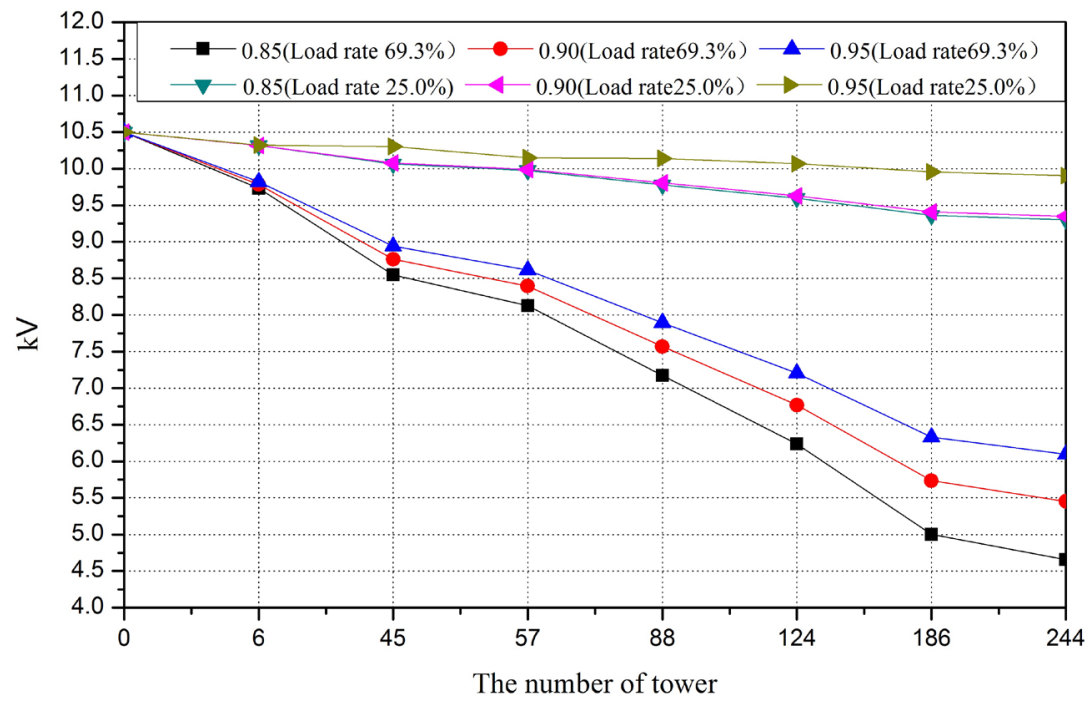

Figure 7. The voltage profile of the line without series capacitor.

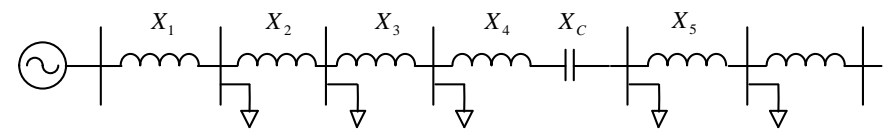

Figure 8. Equivalent single-line diagram of a series compensated distribution circuit. 


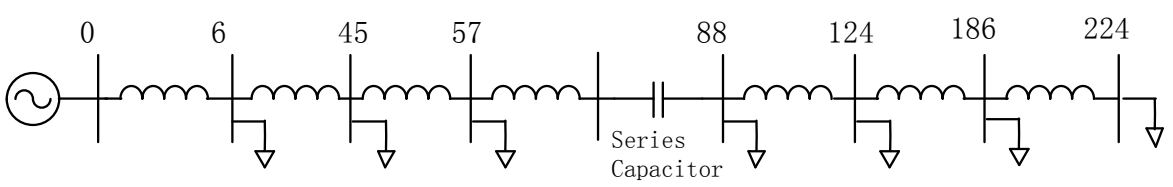

Figure 9. Simulation single-line diagram with series capacitor.

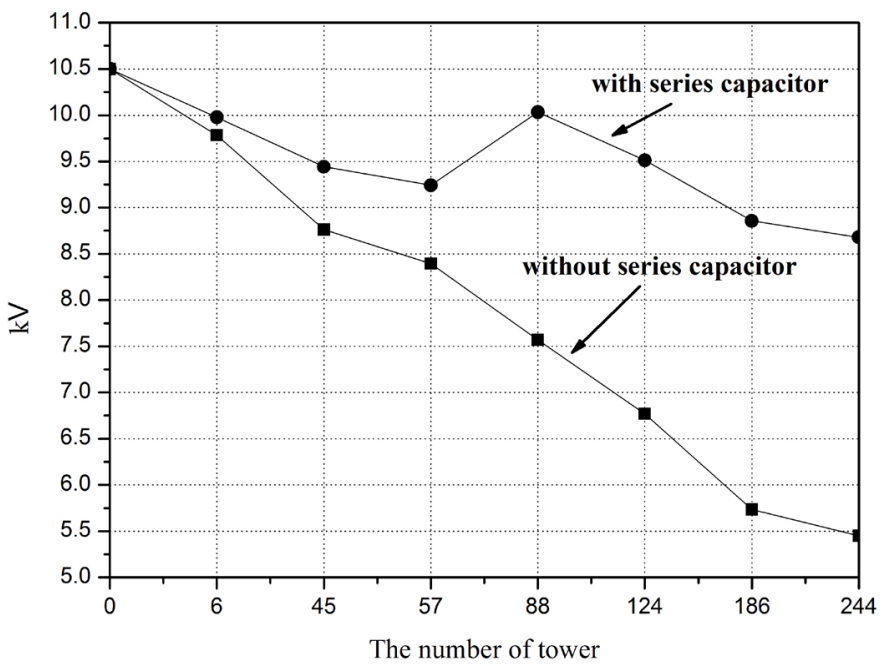

Figure 10. The voltage profile with series capacitor.

It can be seen form Figure 10, after the series capacitor is added, the voltage profile along the line has significantly improved, the voltage at the end of the line improve to $8.7 \mathrm{kV}$, the current of the line is down from $807 \mathrm{~A}$ to $589 \mathrm{~A}$, and the power factor at sending of the line is increased from 0.83 to 0.96 .

In order to achieve the voltage at the end of the line greater than the $9.3 \mathrm{kV}$, the limit transmission power of the line is only $3.33+\mathrm{j} 1.75 \mathrm{MVA}$, if the series capacitor is added, its value can increase to $7.38+\mathrm{j} 2.47 \mathrm{MVA}$, the transmission capacity of the line has been significantly improved.

\section{Series Capacitor Application Considerations}

Series capacitors are used for solving problems on improving voltage quality, transmission capacity and power factor of rural distribution network, but in the real application, some problems must be considered [6].

\section{A. Transformer ferroresonance}

Since the transformer core is saturated nonlinear, when an unloaded or lightly transformer is energized, the excitation current will temporarily reach the values that 8 - 10 times the transformers rated current, this excitation current is called inrush current. Inrush current rapidly changing will cause a huge voltage at the both sides of the capacitor, increase the transformer core saturation level, change the inductance of the transformer, reach the resonance conditions, This phenomenon is usually called ferroresonance. In order to prevent the type of ferroresonance, it should avoid overcompensating, or make the series capacitor bypassed when a transformer is being energized.

\section{B. Induction motor self-excitation}

Many rural distribution network lines has more asynchronous motor, its reactance is one element in the equation that determines the total circuit inductance, when the series capacitor is added, the combination of a series capacitor and the circuit inductive creates a series resonant, and make the induction motor group self-excite, cannot run. When the large motors are starting under certain conditions, if the motor occurring the self-excited, it is likely to be locked in the subsynchronous frequency, and the motor will continue to rotate at a speed governed by that subsynchronous frequency, the motor slip is reduced, resulting in a large current, causing the motor damage. In order to prevent self-excitation, the usual countermeasures can bypass series capacitor during motor starting or connect a damping resistor in parallel with the series capacitor. 


\section{Overvoltage protection of series capacitor}

The added series capacitor is equivalent to reduce the impedance of the line, so when the short-circuit occurred at the location from series capacitor to the end of the line, the short circuit current is more greater than the short circuit current without series capacitor. In order to prevent the capacitor burn because of the overcurrent, it needs to select the capacitor that can withstand extreme short circuit current, or bypass the capacitor when short circuit occurred [7] [8].

\section{Conclusions}

The series capacitor compensation technology has significantly effect on improving the voltage quality, transmission capacity, reducing power loss and voltage fluctuations of the rural distribution network, it has a good prospects.

In the application of the series capacitor compensation technology, In order to prevent problem that the transformer ferroresonance, induction motors self-excited and the overcurrent occur, selecting a reasonable degree of compensation, bypassing capacitor and connecting a damping resistor in parallel with series capacitor and other measures should be taken.

It has other measures for improving the voltage quality of rural distribution network, such as improving the power grid structure, changing the transformer tap position, adding the shunt reactive compensation devices. Each measure has its own advantages and drawbacks with respect to technical and economic issues, therefore we should comprehensively consider a variety of measures.

\section{References}

[1] Zhuo, G.-Y., Jiang, D.-Z. and Liang, Y.-Q. (2013) A Research of D-FSC for Improving Voltage Quality in Distribution Networks. Power Systm Protection and Control, 41, 61-67.

[2] Zhou, G.W. and Li, X. (2005) Reactive Power Compensation for Distribution Network and Its Economic Benefit Analysis. Power Capactior, 1, 1-5.

[3] Zhao, W.-Z. and Wang, D.P. (2010) Application Analysis of Series Reactive Power Compensation in Distribution Network. Low Voltage Apparatus, 5, 37-44.

[4] Lei, X.Z. and Povh, D. (1998) Series Compensation for a Long Distance AC Transmission System. Power System Technology, 22.

[5] Magowan, J.M. (1957) Voltage Performance of Series Capacitors in Transmission and Distribution Lines. The Institution of Electrical Engineers, 2252, 505-516. http://dx.doi.org/10.1049/pi-a.1957.0119

[6] Miske, S.A. (2001) Consideration for the Application of Series Capacitors to Radial Power Distribution Circuits. IEEE Transactions on Power Delivery, 16, 306-318. http://dx.doi.org/10.1109/61.915500

[7] Morgan, L., Barcus, J.M. and Ihara, S. (1993) Distribution Series Capacitors with High-Energy Varistor Protection. IEEE Transactions on Power Delivery, 3, 1413-1419. http://dx.doi.org/10.1109/61.252668

[8] Lat, M.V., Kundu, D. and Bonadie, G. (1990) Overvoltage Protection Scheme for Series Capacitors Banks on High Voltage Distribution System. IEEE Transactions on Power Delivery, 35, 1459-1465.

http://dx.doi.org/10.1109/61.57989 